Open Access

\title{
Facilitating a transition from compulsory detention of people who use drugs towards voluntary community-based drug dependence treatment and support services in Asia
}

Pascal Tanguay ${ }^{1 *}$, Adeeba Kamarulzaman², Apinun Aramrattana ${ }^{3}$, Alex Wodak ${ }^{4}$, Nicholas Thomson ${ }^{5,6}$, Robert Ali ${ }^{7}$, Gino Vumbaca ${ }^{8}$, Gloria Lai ${ }^{9}$ and Anand Chabungbam ${ }^{10}$

\begin{abstract}
Evidence indicates that detention of people who use drugs in compulsory centers in the name of treatment is common in Cambodia, China, Indonesia, Lao PDR, Malaysia, Myanmar, Philippines, Thailand, and Vietnam. The expansion of such practices has been costly, has not generated positive health outcomes, and has not reduced supply or demand for illicit drugs. United Nations agencies have convened several consultations with government and civil society stakeholders in order to facilitate a transition to voluntary evidence- and community-based drug dependence treatment and support services.

In an effort to support such efforts, an informal group of experts proposes a three-step process to initiate and accelerate national-level transitions. Specifically, the working group recommends the establishment of a national multisectoral decision-making committee to oversee the development of national transition plans, drug policy reform to eliminate barriers to community-based drug dependence treatment and support services, and the integration of community-based drug dependence treatment in existing national health and social service systems. In parallel, the working group recommends that national-level transitions should be guided by overarching principles, including ethics, human rights, meaningful involvement of affected communities, and client safety, as well as good governance, transparency, and accountability. The transition also represents an opportunity to review the roles and responsibilities of various agencies across the public health and public security sectors in order to balance the workload and ensure positive results.

The need to accelerate national-level transitions to voluntary community-based drug dependence treatment and support services is compelling - on economic, medical, sustainable community development, and ethical grounds-as extensively documented in the literature. In this context, the expert working group fully endorses initiation of a transition towards voluntary evidence- and community-based drug dependence treatment and support services across the region, as well as the steady scale-down of compulsory centers for drug users. Components of voluntary community-based drug dependence treatment and support services are being implemented in Cambodia, China, Indonesia, Malaysia, and Thailand. However, significant technical and financial support will be required to be allocated from national budgets and by international development agencies in order to complete the transition and reduce the reliance on detention of people who use drugs in Asia.
\end{abstract}

Keywords: Drug dependence, Compulsory treatment, Community-based treatment, Planning, Drug policy reform, Health systems, Principles, Resource mobilization, People who use drugs

\footnotetext{
*Correspondence: pascalembours@gmail.com

'Ozone Foundation, Bangkok, Thailand

Full list of author information is available at the end of the article
}

C Biomed Central

(C) 2015 Tanguay et al. Open Access This article is distributed under the terms of the Creative Commons Attribution 4.0 International License (http://creativecommons.org/licenses/by/4.0/), which permits unrestricted use, distribution, and reproduction in any medium, provided you give appropriate credit to the original author(s) and the source, provide a link to the Creative Commons license, and indicate if changes were made. The Creative Commons Public Domain Dedication waiver (http://creativecommons.org/publicdomain/zero/1.0/) applies to the data made available in this article, unless otherwise stated. 


\section{Background}

The detention of people who use drugs (PWUD) remains a common response to drug use and drug dependence in Cambodia, China, Indonesia, Lao PDR, Malaysia, Myanmar, Philippines, Thailand, and Vietnam [1]. Although this is usually said to be implemented with the aim of treating and rehabilitating PWUD, the unspoken rationale justifying the scale-up of compulsory centers for drug users (CCDU) has included managing parental and community anxieties about drug use in settings where experience with drug use and evidence-based treatment is limited.

The exact number of people detained in the name of treatment in these countries is not known but unpublished data collected by the United Nations Office on Drugs and Crime (UNODC) indicates that almost half a million PWUD are detained in seven countries [2]. To date, the reliance on CCDU has resulted neither in sustained positive treatment outcomes nor in social rehabilitation [3] but rather has been associated with increased HIV risks [4, 5], added stigma and discrimination against PWUD, numerous serious documented human rights violations [6-15], and significant deviations from evidence-based best practices in drug dependence treatment [16-20]. In addition, there has been no significant or sustained decrease in drug production, trafficking, or use in Asia as a result of scaled-up compulsory detention and coercive approaches to drug treatment through CCDU [21]. Expanding the CCDU model has been costly and consumed considerable resources in an area where resources are extremely limited [22]. Evidence suggests that a great number of people currently forced into CCDU are not in need of clinical treatment for drug dependence, thereby exacerbating the cost burden [23, 24].

One significant obstacle to transitioning to communitybased drug dependence and support services ${ }^{1}$ in many Asian countries is the increasing use and perceived problems associated with illicit drug use [25-29]. Significant advocacy efforts have generated increasing acceptance and implementation of opioid substitution therapy services across the region though coverage remains problematically low [30]. While psychosocial interventions are often helpful to address mild and moderate problems associated with amphetamine-type stimulants (ATS), the lack of a pharmacological substitute to effectively address the harms associated with ATS, including dependence, is a significant barrier.

Given the lack of evidence showing either health or criminogenic benefits of CCDU, some countries have initiated a transition to voluntary community-based drug dependence treatment. In order to stimulate dialogue and identify opportunities for national-level transitions towards voluntary community-based drug dependence treatment and support services, the United Nations Economic and
Social Commission for Asia and the Pacific (UNESCAP), the UNODC Regional Office for Southeast Asia and the Pacific, and the Joint United Nations Program on HIV/ AIDS (UNAIDS) Regional Support Team, Asia and the Pacific have convened a series of intergovernmental regional consultations ${ }^{2}$, with the support of the Australian National Council on Drugs, for a final high-level dialogue scheduled to be hosted in the Philippines in September 2015.

\section{Main text}

In an effort to support this process, an informal group of experts $^{3}$ has been established to prepare constructive advice to facilitate and support the operationalization of the national-level transitions and ultimately to develop a more effective and cost-efficient response to drug use and dependence across the region. Following a desk-based review of the evidence and a series of internal and external consultations with key partners and stakeholders, the expert working group proposes a three-step process to initiate national-level transitions.

As a first step, national multisectoral decision-making mechanism should be established with overall responsibility for the transition, including for the development, in consultation with key stakeholders from the public security, public health, and community sectors, including people who use drugs, of a comprehensive action plan or strategy that includes objectives, activities, outcomes, indicators, targets, budgets, timelines, and responsibilities. This tool can provide countries with a critical platform from which to coordinate the transition.

To promote voluntary access to drug treatment and support services, policy approaches to drug use and drug dependence need to shift away from criminalization and punishment to health- and rights-based drug policy measures. For example, instead of arrest, urine drug testing, and detention, governments should consider the adoption of programs that refer and divert people who use and are dependent on drugs to voluntary drug treatment and support services. Drug policy reforms to decriminalize drug use, as recommended by UNAIDS [31] and WHO [32], or depenalization to reduce the penalties associated with drug use should also be considered. Accordingly, national reviews to identify policies that restrict voluntary access to community-based drug dependence treatment and support services should be conducted as a critical step towards achieving an enabling policy environment for the transition.

Finally, reforms should be considered in order to develop and strengthen the various mechanisms underpinning implementation of drug dependence treatment and community-level support services, especially in the public health and public security sectors. These reforms should be accompanied by significant investments in the development of workforce capacity across multiple sectors, including 
among communities of PWUD. More specifically, across the region, opportunities for integrating voluntary community-based treatment and support services are available, especially where low-threshold health and social care services are already being delivered to PWUD. For example, in countries that have invested in harm reduction and scaling up comprehensive HIV prevention, treatment, care, and support services, a number of drug dependence treatment interventions can be integrated at existing service delivery outlets to maximize uptake and increase demand.

The three-step transition process described above should be informed and guided by a range of principles, including ethics, human rights, meaningful involvement of affected communities, and client safety, as well as good governance, transparency, and accountability. Compliance with these different good practice approaches will contribute to reducing the potential unintended negative consequences of the transition and maximize the chance of a successful transition.

The transition should also be considered an opportunity to more effectively balance the national workload associated with drug dependence between sectors, with particular attention for redefining the role of law enforcement in achieving both public security and public health objectives. After all, drug dependence is recognized as a chronic relapsing and remitting health condition that warrants medical attention, irrespective of other normative imperatives. In that context, overall national responses to individuals who use drugs and/or suffer from dependence should be integrated in national systems beyond criminal justice with greater authority delegated to medical professionals.

Finally, the transition towards voluntary communitybased drug dependence treatment and services should result in better health outcomes at the client level. When clients are properly assessed and can voluntarily choose from a menu of drug dependence treatment and support service options, and where those options are available, accessible, and affordable to clients, better results will be generated. Recent evidence from Malaysia indicates a significant improvement in treatment outcomes when clients select drug dependence treatment modalities voluntarily [33].

Components of voluntary community-based drug dependence treatment and support services are currently being piloted, implemented, and evaluated in Cambodia, China, Indonesia, Malaysia, and Thailand [34]. For example, in China, law enforcement are diverting PWUD to the Ping An No. 1 Centre, established by AIDS Care China in 2014; in Cambodia, since 2011, the government, United Nations, and civil society organizations have worked together to provide 1200 PWID with voluntary access to community-based services aligned with international protocols in three provinces [35]; in Indonesia, PWUD have reported preferring accessing drug dependence treatment through Rumah Singgah PEKA's community-based model rather than through government-operated CCDU; and in Malaysia, PWUD leaving from voluntary Cure and Care Centers have been shown to be considerably less likely to relapse compared to those leaving from CCDU [36]. Preliminary reports indicate significant positive results that will require closer scrutiny and evaluation in order to better inform the development of national plans.

\section{Conclusion}

The need to formally initiate national-level transitions towards voluntary community-based drug dependence treatment and support services is compelling-on economic, medical, sustainable community development, and ethical grounds-as extensively documented in the literature. In this context, the expert working group fully endorses initiation of a transition towards voluntary evidence- and community-based drug dependence treatment and support services across the region, as well as the steady scale-down of CCDU.

The expert working group has formulated broad structural-level recommendations to support the formal operationalization of the transition in order to allow significant flexibilities for national level specificities to be addressed in a localized strategy. These structural recommendations recognize the need for national ownership and for responses tailored to the cultural context of each country.

However, implementation of the recommended structural actions and following the overarching principles presented here will likely be insufficient to effectively transition to community-based drug dependence treatment unless significant technical and financial support is allocated from national budgets and by international development agencies. In that respect, the recommendations formulated by the expert working group will be presented officially in Manila, the Philippines, in September 2015, in the context of the Third Regional Consultation on CCDU, in order to facilitate the development of transition plans fully owned at local and national levels and attract support from donor and technical support agencies for such efforts.

\section{Endnotes}

${ }^{1}$ Support services include harm reduction as well as social support services such as employment and housing.

${ }^{2}$ The First and Second Regional Consultations on Compulsory Centres for Drug Users (CCDU) were held in December 2010 in Bangkok, Thailand, and in October 2012 in Kuala Lumpur, Malaysia.

${ }^{3}$ The expert working group is composed of: Prof. Adeeba Kamarulzaman, HIV and Infectious Disease Specialist at the University of Malayia, based out of Kuala Lumpur, Malaysia; Dr. Apinun Aramrattana, Head of the Department of Family Medicine at Chiang Mai University, 
in northern Thailand; Dr. Alex Wodak, Emeritus Consultant for the Alcohol and Drug Service at St. Vincent's Hospital in Sydney, Australia; Dr. Nicholas Thomson, Senior Research Fellow at the University of Melbourne's School of Population and Global Health and a current fellow of the International AIDS Society and the National Institute of Drug Abuse; Dr. Robert Ali, Executive Member of the Australian National Council on Drugs (ANCD), based in Adelaide, Australia; Mr. Gino Vumbaca, Executive Director of the Australian National Council on Drugs (ANCD), based in Canberra, Australia; Gloria Lai, Senior Policy Advisor at the International Drug Policy Consortium, based in Bangkok, Thailand; Mr. Anand Chabungbam is currently the Coordinator at the Asian Network of People who Use Drugs, based in Bangkok, Thailand. The working group operates with support from UNODC Regional Office for Southeast Asia and the Pacific and UNAIDS Regional Support Team, Asia and the Pacific, including secretarial support from consultant Mr. Pascal Tanguay.

\begin{abstract}
Abbreviations
ATS: amphetamine-type stimulants; CCDU: compulsory center for drug users; PWUD: people who use drugs; UNAIDS: Joint United Nations Program on HIV/AIDS; UNESCAP: United Nations Economic and Social Commission for Asia and the Pacific; UNODC: United Nations Office on Drugs and Crime.
\end{abstract}

\section{Competing interests}

The authors declare that they have no competing interests.

\section{Authors' contributions}

All authors coordinated through a series of teleconferences hosted by UNODC and UNAIDS during which a consensus was established on content and process. All authors reviewed, commented, and provided substantive feedback on the content. A final draft was finalized and circulated all authors. All authors read and approved the final manuscript.

\section{Acknowledgements}

We thank Ms. Vladanka Andreeva, Ms. Brianna Harrison, and the Joint United Nations Programme on HIV/AIDS (UNAIDS) as well as Mr. Olivier Lermet and Ms. Karen Peters and United Nations Office on Drugs and Crime (UNODC), who provided logistical and financial support for data collection and development of the manuscript.

The article processing charges for this article were funded by the Joint United Nations Programme on AIDS (UNAIDS) and the United Nations Office on Drugs and Crime (UNODC). The article has undergone the journal's full standard peer review process.

The article was developed based on the current draft of the expert discussion paper referenced in the text. The discussion paper was conceived in September 2014 and was developed under a similar process with more contact between the members of the working group and PT, both through email and skype as well as, where possible, face to face meetings.

\section{Author details}

'Ozone Foundation, Bangkok, Thailand. ${ }^{2}$ University of Malaya, Kuala Lumpur, Malaysia. ${ }^{3}$ Department of Family Medicine, Chiang Mai University, Chiang Mai, Thailand. ${ }^{4}$ Alcohol and Drug Service, St Vincent's Hospital, Sydney, Australia. ${ }^{5}$ University of Melbourne's School of Population and Global Health, Melbourne, Australia. ${ }^{6} J o h n$ Hopkins Bloomberg School of Public Health, Baltimore, United States. ${ }^{7}$ Australian National Advisory Council on Alcohol \& Drugs (ANACAD), Adelaide, Australia. ${ }^{8}$ Australian National Council on Drugs (ANCD), Canberra, Australia. ${ }^{9}$ International Drug Policy Consortium, Bangkok, Thailand. ${ }^{10}$ Asian Network of People who Use Drugs, Bangkok, Thailand.
Received: 27 May 2015 Accepted: 15 September 2015

Published online: 16 October 2015

\section{References}

1. Baldwin S, Thomson N, Dorabjee J, Kumar S. Compulsory detention of people who use drugs in Asia-looking for alternatives. 2012

2. Between 2010 and 2015 , UNODC has collected data from national governments in regards to CCDU, including the number of people detained in such institutions. Responses to the self-administered questionnaires were submitted voluntarily and no data triangulation or validation process was applied.

3. World Health Organization. Assessment of compulsory treatment of people who use drugs in Cambodia, China, Malaysia and Viet Nam: an application of selected human rights principles 2015. www.wpro.who.int/publications/ docs/FINALforWeb_Mar17_Compulsory_Treatment.pdf.

4. Hayashi K, Milloy M-J, Fairbairn N, Kaplan K, Suwannawong P, Lai C, et al. Incarceration experiences among a community-recruited sample of injection drug users in Bangkok, Thailand. BMC Public Health. 2009;9:492. doi:10.1186/1471-2458-9-492.

5. Chen HT, Tuner N, Chen CJ, Lin HY, Liang S, Wang S. Correlations between compulsory drug abstinence treatments and HIV risk behaviors among injection drug users in a border city of South China. AIDS Educ Prev. 2013;25(4):336-48. doi:10.1521/aeap.2013.25.4.336. www.ncbi.nlm.nih.gov/ pubmed/23837811.

6. Amon JJ, Pearshouse R, Cohen JE, Schlieffer R. Compulsory drug detention centres in China, Cambodia, Vietnam, and Laos: health and human rights abuses. Health Hum Rights. 2013;15:2. doi:10.1016/j.drugpo.2013.05.019.

7. Pearshouse R. Compulsory drug treatment in Thailand: observations on the Narcotic Addict Rehabilitation Act B.E. 2545 (2002) 2009. www.aidslaw.ca/ site/compulsory-drug-treatment-in-thailand-observations-on-the-narcoticaddict-rehabilitation-act-b-e-2545-2002.

8. Davis SLM, Triwahyuono A, Alexander R. Survey of abuses against injecting drug users in Indonesia. Harm Reduction J. 2009;6:28. doi:10.1186/1477-7517-6-28.

9. Human Rights Watch. An unbreakable cycle drug dependency treatment, mandatory confinement, and HIV/AIDS in China's Guangxi Province. 2008. http://www.hrw.org/sites/default/files/reports/china1208web.pdf.

10. Human Rights Watch. The rehab archipelago forced labor and other abuses in drug detention centres in Southern Vietnam. 2011. www.hrw.org/report/ 2011/09/07/rehab-archipelago/forced-labor-and-other-abuses-drugdetention-centers-southern.

11. Human Rights Watch. "Skin on the cable"-the illegal arrest, arbitrary detention and torture of people who use drugs in Cambodia. 2010. www.hrw.org/sites/default/files/reports/cambodia0110webwcover.pdf.

12. Human Rights Watch. Public insecurity: deaths in custody and police brutality in Vietnam. 2014. www.hrw.org/report/2014/09/16/publicinsecurity/deaths-custody-and-police-brutality-vietnam.

13. Open Society Institute. At what cost? HIV and human rights consequences of the global "War on Drugs". 2009. www.opensocietyfoundations.org/ reports/what-cost-hiv-and-human-rights-consequences-global-war-drugs.

14. Open Society Institute. Detention as treatment: detention of methamphetamine users in Cambodia, Laos, and Thailand. 2010. www.jhsph.edu/research/ centers-and-institutes/center-for-public-health-and-human-rights/_pdf/ Thomson_OSI_DetentionAsTreatment_2010.pdf.

15. PSI Thailand. Rapid PEER study to strengthen the injecting drug users quality of life programme. 2011. www.scribd.com/doc/265730746/Rapid-PEER-studyto-strengthen-the-injecting-drug-users-quality-of-life-programme.

16. Amon JJ, Pearshouse R, Cohen JE, Schlieffer R. Compulsory drug detention in East and Southeast Asia: evolving government, UN and donor responses. Int J Drug Policy. 2014;25:13-20. doi:10.1016/j.drugpo.2013.05.019.

17. Asian Network of People who Use Drugs. Position paper: compulsory detention of people who use drugs. 2013. http://anpud.org/anpudposition-paper-compulsory-detention-people-use-drugs.

18. Pearshouse R. Compulsory drug treatment in Thailand: observations on the Narcotic Addict Rehabilitation Act B.E. 2545 (2002) 2009. www.aidslaw.ca/ site/compulsory-drug-treatment-in-thailand-observations-on-the-narcoticaddict-rehabilitation-act-b-e-2545-2002.

19. Csete J, Kaplan K, Hayashi K, Fairbairn N, Suwannawong P, Zhang R, et al. Compulsory drug detention centre experiences among a community-based sample of injection drug users in Bangkok, Thailand. BMC Int Health Human Rights. 2001;11:12. www.biomedcentral.com/ 1472-698X/11/12. 
20. Open Society Foundations. Human rights abuses in the name of drug treatment: reports from the field. 2009. www.opensocietyfoundations.org/ publications/human-rights-abuses-name-drug-treatment-reports-field.

21. United Nations Office on Drugs and Crime. World drug report. 2014. www.unodc.org/documents/wdr2014/World_Drug_Report_2014_web.pdf.

22. Cook C, Bridge J, Susie McLean S, Phelan M, Barrett D. The funding crisis for harm reduction: donor retreat, government neglect and the way forward. 2014. www.ihra.net/files/2014/09/22/Funding_report_2014.pdf.

23. Chua-nam S, Jantip S, Yasuwan S, Aramrattana A. Community-owned comprehensive program for methamphetamine users in Northern Thailand. Abstract Presented at the 15th ISAM Annual Meeting, Kuala Lumpur, Malaysia, 21-23 November 2013.

24. Anthony JC. Epidemiology of drug dependence. In: Coyle JT, Philadelphia NC, editors. Davis KL, Charney D. Philadelphia: Neuropsychopharmacology, The Fifth Generation of Progress; 2002. p. 1557-74.

25. Tiezzi S. China's Growing Drug Problem. The Diplomat. 28 May 2015. http://thediplomat.com/2015/05/chinas-growing-drug-problem.

26. Soeriaatmadja W. Indonesia faces growing drug problem. The Straits Times. 22-02-2015. www.asianewsnet.net/Indonesia-faces-growing-drug-problem71966.html.

27. Kentung, Mongla. Getting higher. The Economist. 12 April 2014. www.economist.com/news/asia/21600748-opium-growing-rise-againdrug-consumption-getting-higher.

28. Teehan S. Ecstasy use rising: UN. The Phnom Penh Post. 6 July 2015. www.phnompenhpost.com/national/ecstasy-use-rising-un.

29. Wright L. Asia's meth habit: synthetic drug trade has 'exploded'. DW. 20 August 2014. http://www.dw.com/en/asias-meth-habit-synthetic-drug-tradehas-exploded/a-17868210.

30. Reid G, Sharma M, Higgs P. The long winding road of opioid substitution therapy implementation in South-East Asia: challenges to scale up. Journal of Public Health Research. 2014 3:204. doi:10.4081/jphr.2014.204. www.researchgate.net/publication/265213252_The_Long_Winding_ Road_of_Opioid_Substitution_Therapy_Implementation_in_South-East_ Asia_Challenges_to_Scale_Up.

31. WHO. Consolidated guidelines on HIV prevention, diagnosis, treatment and care for key populations. 2014.

32. UNAIDS. The GAP Report. 2014

33. Ghani MA, Brown S-E, Khan F, Wickersham JA, Lim SH, Dhaliwal SK, et al. An exploratory qualitative assessment of self-reported treatment outcomes and satisfaction among patients accessing an innovative voluntary drug treatment centre in Malaysia. Int J Drug Policy. 2015;26(2):175-82. doi:10.1016/j.drugpo.2014.10.002. Epub 2014 Oct 28.

34. Tanguay P, Aramrattana A, Wodak A, Kamarulzaman A, Ali R, Thomson N Lai G, Chabungbam A, Vumbaca G. In press. Discussion paper: Transition from compulsory centers for drug users to voluntary community-based treatment and services. 2015.

35. UNODC. Supporting access for drug users to health and social care in Cambodia_case studies of community-based services in Banteay Meanchey, Battambang and Stung Treng provinces. 2015.

36. Kamarulzaman A. Transformation from Compulsory Drug Detention Centers to Ambulatory Care Programs, Presentation delivered on 11 February 2015 at the Informal Partner Consultation on the Compulsory Centers for Drug Users in East and Southeast Asia in Bangkok, Thailand.

\section{Submit your next manuscript to BioMed Central and take full advantage of:}

- Convenient online submission

- Thorough peer review

- No space constraints or color figure charges

- Immediate publication on acceptance

- Inclusion in PubMed, CAS, Scopus and Google Scholar

- Research which is freely available for redistribution

Submit your manuscript at www.biomedcentral.com/submit 